\title{
From therapeutic landscapes to healthy spaces, places and practices: a scoping review
}

Article

Accepted Version

Creative Commons: Attribution-Noncommercial-No Derivative Works 4.0

Bell, S. L., Foley, R., Houghton, F., Maddrell, A. and Williams, A. M. (2018) From therapeutic landscapes to healthy spaces, places and practices: a scoping review. Social Science \& Medicine, 196. pp. 123-130. ISSN 0277-9536 doi: https://doi.org/10.1016/j.socscimed.2017.11.035 Available at https://centaur.reading.ac.uk/74329/

It is advisable to refer to the publisher's version if you intend to cite from the work. See Guidance on citing.

To link to this article DOI: http://dx.doi.org/10.1016/j.socscimed.2017.11.035

Publisher: Elsevier

All outputs in CentAUR are protected by Intellectual Property Rights law, including copyright law. Copyright and IPR is retained by the creators or other copyright holders. Terms and conditions for use of this material are defined in the End User Agreement.

www.reading.ac.uk/centaur 
Central Archive at the University of Reading

Reading's research outputs online 


\section{From therapeutic landscapes to healthy spaces, places and practices: A}

\section{scoping review}

Authors: Sarah L. Bella*, Ronan Foley ${ }^{\mathrm{b}}$, Frank Houghton ${ }^{\mathrm{c}}$, Avril Maddrell ${ }^{\mathrm{d}}$, Allison M. Williams ${ }^{\mathrm{e}}$

*Corresponding author

a European Centre for Environment and Human Health, University of Exeter Medical School, Truro, TR1 3AE, Cornwall, UK, Sarah.Bell@exeter.ac.uk,

${ }^{\mathrm{b}}$ Department of Geography, Maynooth University, Maynooth, Co. Kildare, Ireland, ronan.foley@nuim.ie

${ }^{c}$ College of Health Science \& Public Health, Eastern Washington University, Spokane, WA, USA, fhoughton@ewu.edu

d School of Archaeology, Geography and Environmental Science, University of Reading, Reading, UK, avril.maddrell@reading.ac.uk

e School of Geography and Earth Sciences, McMaster University, 1280 Main Street West, Hamilton, Canada, awill@mcmaster.ca

Abstract: The term 'therapeutic landscapes' concept was first coined by health geographer, Wilbert Gesler, in 1992 to explore why certain environments seem to contribute to a healing sense of place. Since then, the concept and its applications have evolved and expanded as researchers have examined the dynamic material, affective and socio-cultural roots and routes to experiences of health and wellbeing in specific places. Drawing on a scoping review of studies of these wider therapeutic landscapes published between 2007 and 2016, this paper explores how, where and to what benefit the 'therapeutic landscapes' concept has been applied to date, and how such applications have contributed to its critical evolution as a relevant and useful concept in health geography. Building on themes included in two earlier $(1999,2007)$ edited volumes on Therapeutic Landscapes, we summarise the key themes identified in the review, broadly in keeping with the core material, social, spiritual and symbolic dimensions of the concept initially posited by Gesler. Through this process, we identify strengths and limitations of the concept and its applications, as well as knowledge gaps and promising future directions for work in this field, reflecting critically on its value within health geography and its potential contribution to wider interdisciplinary discussions and debates around 'healthy' spaces, places and related practices. 
Key words: Therapeutic landscapes; therapeutic mobilities; therapeutic assemblage; wellbeing; scoping review.

\section{Introduction: The healing power of place}

Drawing on theories in cultural ecology, structuralism and humanism, the therapeutic landscapes concept was first posited in 1992 by Wilbert Gesler as a vehicle for exploring why certain environments seem to contribute to a 'healing sense of place' (Gesler, 2003). Such environments were defined as therapeutic landscapes, 'where the physical and built environments, social conditions and human perceptions combine to produce an atmosphere which is conducive to healing' (Gesler, 1996: 96). This definition conveyed the importance of understanding the physical and social health-promoting qualities of a given space, but also the more subjective ways in which people might interpret and use that space (Cattell et al., 2008).

A first edited volume by Williams (1999) brought together early applications of the concept, focusing on the literal relationships between health and place. Studies conducted at this time explored the healing properties of widely acknowledged, 'extraordinary' places of healing, such as sacred pilgrimage sites, groves and hot springs (Gesler, 1993; 1996; 1998). Soon, however, researchers extended the concept to incorporate the health promoting (as well as healing) qualities of therapeutic spaces and the therapeutic value of everyday spaces. These included both aesthetic qualities and more imperceptible social networks offering a sense of security and inclusion (Smyth, 2005; Wakefield and McMullan, 2005). Alongside these developments, criticisms emerged that 'over time, researchers have done little more than claim certain phenomena to be therapeutic landscapes', using the term rather like 'an explanatory bumper sticker' (Andrews, 2004: 308).

The assumption that places were somehow intrinsically therapeutic raised particular concern, prompting greater recognition of the relational nature of people's therapeutic landscapes. 
In particular, Conradson (2005: 338) argued that therapeutic landscape experiences should be more critically approached as 'a relational outcome, as something that emerges through a complex set of transactions between a person and their broader socio-environmental setting'. This relational kernel has since been embraced more widely amongst health geographers, resulting in notions of 'therapeutic taskscapes' (Dunkley, 2009), 'therapeutic assemblage' (Foley, 2011) and 'therapeutic mobilities' (Gatrell, 2013), each reflecting on the dynamic material, affective and socio-cultural roots and routes to experiences of health and wellbeing in place. Williams' (2007) second edited collection, 'Therapeutic Landscapes', further responded to critiques and examined the continuing evolution of the term, including emerging ambiguities and contestations.

In this scoping review of the literature published since 'Therapeutic Landscapes' (Williams, 2007), we examine how the subject has changed over the last ten years and how different critical challenges and deepening knowledge of the subject have played out within health geography. Scoping reviews present a valuable opportunity to 'identify the extent and nature of research evidence' (Grant and Booth, 2009: 101) across a broad topic of interest, balancing breadth with depth of insight in order to gain a preliminary understanding of research gaps in the field (Arksey and O'Malley, 2005). Our review of the therapeutic landscapes literature published from 2007 to 2016 was informed by the research question: 'How, where and to what benefit has the "Therapeutic Landscapes" concept been applied to-date, and how have such applications contributed to its critical evolution as a relevant and useful concept in health geography?'

\section{Review Methodology}

Following the scoping review approach set out by Arksey and O'Malley (2005), initial searches were conducted in May 2016, using three search terms ("therapeutic landscape", "therapeutic mobilities", "therapeutic network") within three comprehensive electronic databases (Web of Science, ProQuest, Scopus). Recognising the limitations of journal indexing within electronic databases, 
additional manual searches were conducted to identify recent publications within journals known to have a significant publication record in this area of research (checking the contents tables of 'Health and Place', 'Social Science and Medicine', 'Social and Cultural Geography'), as well as scanning reference lists of shortlisted sources. Although this paper focuses on sources published since 2007, the search dates were initially selected to identify sources published since 1992, when the therapeutic landscapes term was first posited by Gesler. The full search strategy - including search fields, retrievals, inclusion/exclusion criteria, and approaches to quality appraisal and source charting - is included as Supplementary Material. Further database searches, conducted in December 2016, used the same procedures to identify new sources published since May 2016.

Of the 252 sources identified in total, 161 were published since 2007. For the purposes of this paper, we summarise the key review findings in line with the core material, social, spiritual and symbolic dimensions of the concept as initially posited by Gesler (1992), exploring developments in its application since Williams' (2007) edited collection, 'Therapeutic Landscapes'. Although we examine each dimension in turn for analytical purposes, we acknowledge their interdependence in shaping people's therapeutic experiences in practice. In our discussion, we reflect on contestations of the term, identifying strengths and limitations of the concept and its applications, alongside gaps in the knowledge base. We also propose future directions for the concept, reflecting critically on both its value within health geography and its potential contributions to wider interdisciplinary discussions and debates around 'healthy' spaces, places and related practices. Although we focus primarily on the therapeutic landscapes literature identified via the scoping review, we do touch on wider bodies of literature where appropriate throughout the paper.

\section{Material/physical dimensions of place: "palettes of place"}

The health and healing benefits of space and place have received widespread cross-disciplinary research attention to-date, with a particular focus over the last ten years on the presence and role 
of specific 'green' and 'blue' materialities found therein. Here we reflect on a subset of this literature - that which draws explicitly on Gesler's concept of therapeutic landscapes (be it in isolation or alongside related concepts) - to explore the everyday experiences and practices that make such places health-enabling for individuals and communities. We use the term 'palettes of place' to examine how and why diverse, interlinked materialities may enable health at different times and for different people. Reflecting earlier therapeutic landscapes research, studies published over the past ten years have examined the influence of material settings ranging from large-scale (countryside, coasts and seaside) through meso-scale (urban parks and riverine spaces) to micro-scale environments (hospitals and clinics, woods, gardens, and allotments). The scope of earlier work has been extended through studying diverse populations, including varied ages, genders, cultures, bodily abilities and place-specific practices.

\subsection{Developing palettes of place}

The material benefits of so-called 'green' space remains a constant trope within the therapeutic landscapes literature, offering rich insights into how it feels to encounter and move through such settings. The enabling power of 'nature' remains central, with ongoing research identifying benefits of interactions with woodlands, parks and gardens (Milligan and Bingley, 2007, Plane and Klodawsky, 2013). This speaks to health education and promotion initiatives, within which elements of outdoor exercise like yoga, or embodied mobilities like walking, are enacted in and through green space (Lea, 2008; Doughty, 2013; Gatrell, 2013). Originally subsumed within green space, blue spaces have become sites of increased attention, with water at the centre of a range of outdoor spaces perceived to promote healthy living (Foley and Kistemann, 2015). Recent work has focused on an everincreasing range of 'blue' settings (islands, cities, rivers, coasts, beaches, lakes) and practices (swimming, promenading, retirement, walking) that mark the beginnings of a burgeoning study area (Kearns et al., 2014; Bell et al., 2015; Foley, 2015; Lengen, 2015; Thomas, 2015). A specific 
environmental health interest in the urban blue has an earlier provenance but remains important in city-based studies, both within and beyond the therapeutic landscapes literature (Völker and Kistemann, 2013, 2015).

Blue/Green spaces can be seen as pristine, even aspirational, and yet therapeutic materialities come in many shades; with browns and greys representing built environment spaces such as allotments, community gardens, abandoned or vacant plots that act as valuable interstitial micros-spaces for restoration and wellbeing (Pitt, 2014; Findlay et al., 2015; Houghton and Houghton, 2015; Völker and Kistemann, 2015). Studies also consider a more blurred palette, such as the always-mobile greens, blues and greys of land/water interfaces (Foley, 2015) or place interactions of brightness and shadow and linear mobilities evident whilst walking in forests and by streams (Doughty, 2013; Völker and Kistemann, 2013). Shadings can shift in positive and negative ways, wherein perceptions of lakes, for example, shift from spaces of light and reflection to spaces of darkness and oblivion (Lengen, 2015). The differential conversations and subjects emerging from this work create space for voices of difference but also more place-responsive narratives.

There has been a slow but steady acceptance of a hybrid green-blue in the past ten years that draws attention to a new 'palettic' understanding of therapeutic landscapes in which hitherto fixed understandings of green and blue space are increasingly under critical scrutiny. Notably, the growing focus within and beyond the therapeutic landscapes literature on affective, embodied, multisensory outdoor experiences raises interesting challenges to this 'palettic' approach (Spinney, 2006; Straughan, 2012; Nettleton, 2015). As discussed by Brown (2016), for example, by framing the environment primarily through colour, there is a risk of overlooking the wider textures, terrains, auditory tones, smells and sensations that are felt through the body to render such encounters therapeutic or otherwise. In this way, perhaps a shift towards palettic 'sensescapes' might better equip researchers to engage with corporeal contingency and embodied difference (Macpherson, 2016; Meijering et al., 2016), potentially pointing to a useful point of intersection with wider literature on sensuous geographies, geographies of disability and differential mobilities (Rodaway, 
1994; Burns et al., 2009, 2013; Parent, 2016).

\subsection{Developing spatio-temporal evidence: how therapeutic places and spaces work}

Over the last ten years, increasing efforts have been made to examine how therapeutic places and spaces work, offering deeper uncoverings of how dynamic experiential, embodied and emotional geographies assemble to maintain and promote health and wellbeing for different individuals and groups at different times (Findlay et al., 2015; Foley, 2015; Bell et al., 2017). This work seeks to incorporate a fuller validation (even re-valuing) of subjective experiences, identifying other ways of uncovering relational health effects (Cooper Marcus and Sachs, 2013). In such work, a concern for innovative methodologies and measurable benefits remains important, while an emphasis on special or sub-groups - children and schools, older cohorts, people with disabilities or mental illness uncovers more differentiated understandings of how and why green spaces become therapeutic or otherwise (Duff, 2012; Bell et al., 2014). Many more groups and types of green/blue space remain to be explored, as does the assumption of automatic therapeutic gains; for example, research on asthma sufferers identified a counter-intuitive preference for urban space given the high level of pollen in the countryside (Edgley et al., 2011).

One increasing focus of recent therapeutic landscapes research is the use of both mobile and in-situ approaches; using GPS, accelerometers and photo/video elicitation interviews to explore time and site-specific wellbeing responses of considerable depth (Coleman and Kearns, 2015; Bell et al, 2015, 2017). Looking beyond the therapeutic landscapes tradition, improved access to digital spatial data, time-series longitudinal surveys and remote/online data collection (Pearce et al., 2016; Kestens et al., 2016) opens up the potential to examine further the diverse temporal qualities and contingencies of people's everyday therapeutic place experiences. As yet under-explored within the therapeutic landscapes literature is the potential to combine physiological measures with in-depth narrative methods; such mixed method approaches may open up opportunities for policy dialogue 
concerning the mechanisms - physical, social and emotional, direct and managed - by which exposure to diverse socio-material-affective assemblages in place may improve embodied health states for different individuals at varied times. This may occur in the course of an unfolding moment (reflecting the wider literature on more-than-representational experiences of health and wellbeing e.g. see Smith and Reid, 2017), a day, a year or the wider life course (Coleman and Kearns, 2015; Bell et al., 2017).

There is still a traceable tension between pathogenic and salutogenic approaches that can be framed around subtle distinctions between something that is valuable (in its own right) as an emotionally framed and experiential finding or value-able as a measurable and potentially commodifiable result. As such, it remains important to clarify the complementary nature of multiple perspectives and methodological approaches as these continue to underpin the empirical relevance of therapeutic landscapes studies. The following sections extend discussions of materialities, spaces, settings and tensions into broader arenas, highlighting the increasingly porous, hybrid and relational nature of people's therapeutic geographies.

\section{Social dimensions of place: "the empathetic encounter"}

The social dimensions of therapeutic place encounters have continued to attract substantive attention within the therapeutic landscapes literature over the last ten years, particularly within contexts characterised as settings of 'care'. These range from formal health care institutions - such as community hospitals, psychiatric hospital wards and hospices - to more informal spaces of care within the wider community, such as cafes, public libraries, community pharmacies and activity clubs. Populations within these studies include long-term carers, and individuals living with myriad mental health conditions, complex disabilities, terminal and/or chronic physical illnesses (such as stroke, cancer, dementia), older age and/or experiences of social deprivation and marginalisation. Here we discuss two themes recurring through this literature, concerning social tensions between 
surveillance and sanctuary in care, and the balance of emotional retreat and everyday sociality within therapeutic assemblages designed to promote coping in the face of liminality.

\subsection{Surveillance and sanctuary}

Building on early interests in post-asylum geographies, a number of studies published over the last ten years have examined the repercussions of deinstitutionalisation for the management of mental health. Although traditional asylums were often stigmatised as settings of social control and incarceration (Curtis et al., 2007; Wood et al., 2015), they offered a secure space to 'be' for many long-term residents; a space where they could engage in therapeutic pursuits, such as farming, horticulture, outdoor sports and walks (Eastoe, 2016). As discussed in the wider critical geographies of mental health literature, closure of these institutions led to the relocation of former residents into temporary psychiatric wards or the wider community, with many left searching for elusive 'insane' spaces in which to express themselves freely without judgement (Parr, 1997). As noted by Collins et al. (2016: 12), 'safe and negotiable landscapes offering choice and meaning seem lost in the complex environments that constitute modern hospital outpatient and community facilities'.

The new psychiatric wards were designed as transient spaces for patients, intended as a 'stepping stone' before re-commencing life elsewhere (Curtis et al., 2009). Studies suggest that service users within these wards missed the moments of freedom from social surveillance offered by the extensive outdoor grounds of the older asylum settings (Curtis et al., 2009), seeking alternative opportunities to appropriate more private spaces for themselves, even if fleetingly; spaces to resist the medical 'gaze' and power-laden norms of the institution, to temporarily go 'off the map' and reassert a sense of control over their identity (Muir-Cochrane et al., 2013; Wood et al., 2013a,b). Reflecting on the experiences of a psychiatric self-help group, Laws (2009) highlights a transient 'seizing' of marginalised, disordered public spaces perceived to mirror their dissident moods, such as neglected park areas, burnt-out summerhouses and cordoned-off roundabouts. 
The challenges for mental health service users following the political shift towards deinstitutionalisation of psychiatric care cohere around the sense of anxiety, abandonment and increased risk of relapse for patients following premature discharge from these wards; leading to a life of transience between insecure housing and homelessness (Curtis et al., 2009). This transience is also seen amongst individuals living with substance abuse; whilst temporary treatment programmes offer short-term assistance, they rarely address the material deprivation and social oppression faced in people's everyday lives (Love et al., 2012). For such individuals, the therapeutic value of regular and long-term access to empathetic, non-threatening, non-judgemental forms of social interaction is noted in studies identifying how therapeutic assemblages can emerge as a result of informal care 'work' within the wider community. This is apparent in, for example, Warner et al.'s (2013) study of a seemingly unremarkable café located within one of the most deprived wards in the UK, and Brewster's (2014) study of public libraries as 'recession sanctuaries' for individuals with mental health conditions. Taken together, these findings emphasise the importance of the 'therapeutic encounter' in promoting atmospheres of care (discussed in earlier work outside of the therapeutic landscapes tradition by Conradson, 2003), offering opportunities for positive experiences of relatedness. Importantly, such opportunities are not confined to human encounters; interactions with other animals (e.g. wildlife, farm animals, domestic pets) can play a powerful role, with these non-human animals potentially acting as co-participants and co-constituents of therapeutic encounters (Gorman, 2016).

\subsection{Liminality, emotional retreat and everyday sociality}

The therapeutic nature of empathetic, undemanding forms of social relatedness is also reflected within more recent work on 'affective sanctuaries' (Butterfield and Martin, 2016); therapeutic sociomaterial-affective assemblages affording a delicate balance between emotional retreat and everyday sociality. These sanctuaries are sought out by individuals experiencing a sense of liminality, 
for example those cast out of their familiar lives by the onset of chronic, acute or terminal illness (Moore et al., 2013; Meijering et al., 2016). Such individuals need time and space to reflect on the meaning of illness for their bodies (a micro-scale therapeutic landscape - see English et al., 2008; Liamputtong and Suwankhong, 2015), their everyday routines, relationships, interests, senses of self and hopes for the future (Carter et al., 2016).

The importance of 'third places' as affective sanctuaries emerges in this work, described as 'havens of sociability' away from home (the first place) or work (the second place) or, in this case, 'a place apart from home and hospital' (Glover and Parry, 2009: 98). With hospitals linked to intense bodily surveillance and treatment, and home a site of careful emotional regulation, third places can provide otherwise elusive opportunities for emotional refuge and non-demanding social interaction. This is apparent in studies of Gilda's Clubs and Maggie's Centres; settings specifically designed for and dedicated to individuals diagnosed with, surviving or supporting others with cancer (Glover and Parry, 2009; Parry and Glover, 2010; Glover et al., 2013; Butterfield and Martin, 2016). These settings combine practical, emotional and social support to promote a casual 'home-like' atmosphere (focusing on 'idealised' notions of home as a space of belonging, security and comfort). Through providing a safe space for self-expression, candid dialogue, as well as more solitary immersion and a temporary sense of escape, these settings seek to catalyse what Moore et al. (2013) describes as a shift from drifting (living with chaos, placelessness and uncertainty), to shelter (feeling safe, more comfortable and building a sense of belonging), to venturing (seeing beyond the sphere of illness, trying new pursuits, learning to 'live' again despite the constraints of illness). Other studies have illustrated how dedicated community spaces - such as 'Men's Sheds' and 'Memory Boxes' - can re-instil this desire to 'venture' amongst individuals feeling increasingly alienated from their everyday living environments and networks, facilitating rare moments of exploration, absorption and inclusion (Milligan et al., 2015; Phillips et al., 2015).

Although community care settings typically aim to foster an atmosphere of inclusivity, the absence of certain 'bodies' therein has been critiqued, particularly those of black and minority ethnic 
groups; as noted by Glover et al. (2013), it can be 'too easy' to normalise the absence of certain groups, attributing it to 'naturally' different ways of coping. As yet, the therapeutic landscapes literature largely fails to understand why these settings are not emotionally resonant for absent individuals and groups, or how their needs could best be embraced within such atmospheres of care; for example, is self-exclusion a product of 'misrecognition' (Bourdieu and Wacquant, 1992) whereby historically 'othered' groups take for granted that such settings are not 'for them', or are other dynamics at play?

Examples of social exclusion are also apparent within the limited studies applying the therapeutic landscapes concept within the Global South, emerging in terms of both health practices and health discourses. For example, in terms of health practices, Giles-Vernick et al. (2016) convey the deep-seated structural barriers encountered by low-income parents in the Central African Republic seeking safe, affordable treatment for children with severe diarrhoea, largely due to the legacy of structural adjustment policies. In terms of health discourses, Mackian (2008) highlights how media constructions of health in Uganda persistently fail to challenge the disempowering social pressures and expectations imposed on women, and their subordination in society. MacKian calls for greater recognition of the intangible (discursive or otherwise) landscapes that affect people's health in subtle yet profound ways, noting that the construction of therapeutic landscapes is always in part a political project, empowering some whilst marginalising others.

\section{Spiritual dimensions of place: "spiritual healing"}

Spirituality and spiritual healing were core components of Gesler's (1993) initial concept of therapeutic landscapes, which has since been employed to understand several different types of pilgrimages, formal and informal, religious and secular (Foley, 2013; Harris, 2013; Maddrell, 2011, 2013). Studies emphasise the assemblage character of both pilgrimage sites and routes, experienced to varying degrees as embodied-emotional-spiritual-social experiences. Given the heritage status of 
many historic religious sites, the interface of beliefs and experience present a methodologically challenging but rich nexus of therapeutic sites and practices (Foley 2013; Maddrell et al., 2015; Maddrell and Scriven 2016), although Bigante (2015) highlights the need for more research within non-Western spiritual and cultural contexts of healing.

The narratives surrounding pilgrimage sites have changed over time, with many pilgrims seeking 'healing on a holistic spectrum', not just a physical cure for a disease/ailment (Harris, 2013: 23). Through rituals, prayer and mass celebration, the symbolic and social environments of pilgrimage sites can foster a sense of community and belonging deemed conducive to spiritual healing (Williams, 2010). In this way, pilgrimage constitutes a therapeutic mobility that connects pilgrims through social interactions, physical activity, and direct engagement (Foley, 2013; Maddrell, 2013a). Most pilgrims tend to mention God or some form of spiritual feeling when sharing their experience (Maddrell, 2013b), highlighting the capacity of therapeutic landscapes to inspire participants to engage with their spirituality, including those without a formal religious affiliation. Furthermore, a theme of silence and 'space apart' emerges within the literature (Conradson, 2007, Maddrell, 2013b), particularly amongst individuals whose everyday life rarely affords moments of stillness or relief from the pressures of both work and family life.

While the experience of pilgrimage is typically a mobile one, increasing digital connectivity provides 'virtual' pilgrimage experiences to people seeking spiritual renewal who cannot travel due to time, mobility or financial restrictions. A study of four Catholic cyber-pilgrimages identified therapeutic elements online (i.e. sacred symbols), but being removed from the embodied contextual encounter with the spiritual place in real time made it difficult to fully experience the healing properties of each site, suggesting an exclusive element to the notion of therapeutic pilgrimage (Williams, 2013). Recognising that spaces designed for worship "can differently open ... capacities and affective atmospheres of the sacred, while simultaneously, circumscribe such capacities because of expected outcomes and contrived participatory 'manners'", Williams (2016: 49) also explored how spirituality played out in a semi-monastic Pentecostal community providing treatment for drug 
addiction. Notably, such spaces led to feelings of disconnection for those who were disengaged from the 'mandatory nature of worship space' (Williams, 2010: 53), which raises important questions about the ambiguous role of spirituality in the therapeutic landscapes of such marginalised populations.

\section{Symbolic dimensions of place: the importance of culture}

The symbolic dimensions of therapeutic place assemblages - particularly at the socio-cultural level are often overlooked in more recent work on therapeutic landscapes, and yet cultural norms, narratives and expectations can play a powerful role in shaping people's affective experience of space (Edensor 2012). We reflect on this here, drawing on emerging applications of the therapeutic landscapes concept in three broad contexts: the arts (with their potential to unsettle and thereby raise awareness of more pre-reflective cultural dispositions and processes); migration (where people may be forced to adapt their therapeutic place experiences to new settings with different cultural norms and expectations); and amongst indigenous groups (whose deep-seated cultural connections to land and landscape have often been disrupted through the history and consequences of colonisation and dispossession).

\subsection{The Arts}

Despite the mainstreaming of art therapy, the last decade has seen relatively little research examining therapeutic landscapes through the arts, or the role of the arts in bringing to public attention the more intangible socio-cultural processes that can render settings therapeutic for some yet risky or exclusionary for others. What little research exists has focused on traditionally examined media, such as literature and creative non-fiction. For example, Willis (2009) used Terry Tempest Williams' 'Refuge' and Linda Hogan's 'The Woman Who Watches Over the World' to examine healing and grief, mirroring the growing focus on everyday places of healing apparent within the wider 
therapeutic landscapes literature. Houghton and Houghton (2015) used Richard Mabey's text 'The Unofficial Countryside' to address issues of scale, attention, pace and land type in relation to therapeutic environments. Through an exploration of what he termed 'edgelands', they proposed that post-industrial sites and interfacial 'hybrid' zones had significant therapeutic potential, albeit at a micro-scale. In line with the evolving mindful turn in Geography, they advocated the potential utility of mindfulness as an approach through which to investigate self-environment interactions.

With the exception of music and painting, there is a surprising dearth of engagement with the therapeutic landscapes concept through other media such as film, television or photography. Rose and Lonsdale (2016) highlight the therapeutic value amongst older adults of re-imagining past landscapes of personal significance through engaging in participatory painting initiatives; a feature also of work by Lengen (2015) within Swiss psychiatric clinics. Meanwhile, from a somewhat different perspective, Evans et al. (2009) examine environmental artwork located within Canadian hospital waiting rooms, suggesting that the 'mastery' of culture over nature depicted in landscape artwork resonates with the type of mastery implicit in the 'medical gaze', while also offering moments of escape for patients faced with illness; providing windows into therapeutic 'imaginaries' or 'therapeutic landscapes of the mind' (Gastaldo et al., 2004). In the area of music, Evans (2014) draws on affect theory to listen for therapeutic landscapes in the work of musician and producer, Brian Eno, whilst Andrews et al. (2011) explore the affective power of music in fostering social movements and influencing politicians to act to improve wellbeing.

\subsection{Indigenous peoples}

Examinations of the therapeutic landscapes concept in the literature relating to indigenous peoples are largely dominated by the history and consequences of colonisation and dispossession (Panelli and Tipa, 2007; Gone, 2008; Smith et al., 2010). This forcefully articulates a clear and intimate connection between environmental health ('Mother Earth', Smith et al., 2010), access to traditional landscapes and the health of indigenous peoples. An important focus of recent work has been 
complex and evolving relationships between indigenous peoples and local lands caused by environmental contamination resulting from industrial processes and mining (Smith et al., 2010). For example, in their study of Aamjiwnaang First Nation residents in Ontario, Canada, Smith et al. (2010) examined how industrial pollution resulting from petrochemical and chemical plants have often negatively influenced attitudes towards traditional therapeutic landscapes. Ambivalent attitudes towards 'Mother Earth' were noted as 'residents are forced to reflexively re-evaluate the meanings they have thus far attached to such places' (Smith et al., 2010: 81).

An overarching theme emerging in this body of literature relates to critiques of the provision of health and social services in would-be therapeutic landscapes for indigenous peoples; as one might anticipate given cultural differences, a major focus relates to mental health services (Gone, 2008; Goodkind et al., 2015). Traditional Western biomedical approaches to mental health issues have been critiqued (Goodkind et al., 2015), sometimes in great depth (Gone, 2008), and suggestions made as to how community development, cultural awareness, inter-personal connectedness, separate spaces and links to natural environments could improve community health and wellbeing (Wendt and Gone, 2012; Goodkind et al., 2015). Whilst the therapeutic landscapes concept could be valuable in terms of sensitising researchers to the need to account for crosscultural differences in how diverse indigenous groups conceptualise notions of health and wellbeing, and the symbolism underpinning varied indigenous relationships to the land and landscape, such efforts require genuinely cross-cultural multi-disciplinary research teams that will prioritise emic over etic perspectives (see, for example, discussions by Panelli, 2008).

\subsection{Migration}

Recent studies incorporating both the topic of migrants and the concept of therapeutic landscape have focused primarily on refugee populations, although critical links have yet to be made between notions of affective sanctuary emerging within the therapeutic landscapes literature (Butterfield and Martin, 2016) and the more specific "Cities of Sanctuary" movements examined within wider 
geographical literature on migration and exclusionary asylum regimes (see, for example, Bagelman, 2013; Darling, 2017).

Studies of Canadian refugees appear dominant in the relatively small pool of literature examining the therapeutic landscape experiences of migrant groups to date (Dyck and Dossa, 2007; El-Bialy and Mulay, 2015; Agyekum and Newbold, 2016). Some of this literature has focused on discrete microenvironments; for example, a gender-based approach comparing the experience of Afghani and South Asian women noted the importance of home and traditional foods as the focus of efforts to construct healthy spaces (Dyck and Dossa, 2007). At a wider spatial scale, other research has explored the adverse impacts of urban design and climate, as well as the positive impacts of locally accessible natural environments on health (El-Bialy and Mulay, 2015).

The importance of migrant constructions of a sense of place and a (in some cases, 'transnational' cross-cultural) sense of belonging is stressed throughout this literature (for example, Chakrabarti, 2010). This place making and re-territorialisation is noted as integral to the restoration and development of the health of migrants (Sampson and Gifford, 2010). The importance of religion for migrants is also discussed by Agyekum and Newbold (2016), acting both as an anchor and an enabler in new environments through enhancing access to valued socio-cultural and material resources. As noted in the wider literature, migrants' religious practices, such as pilgrimage, can constitute vital spaces of trans-national caring, spiritual and social renewal (Notermans, 2016); likewise secular family outings such as picnics and visits to theme parks or heritage sites merit further consideration in the continuum of therapeutic landscapes and environments.

\section{Discussion: Contested terminologies, contested experiences, diverse needs}

The breadth of contexts in which the 'therapeutic landscapes' concept has been - and continues to be - applied to-date, suggests this remains a lively field of research within health geography, although there are growing concerns about the creative constraints imposed by the term itself. For 
some, these centre on the overly biomedical connotations of the word 'therapeutic' (reinforced by its parallel use within medical circles to refer to the pharmaceuticals available for treating specific conditions), and its somewhat ambiguous meaning; what are people seeking to cure or heal through their so-called therapeutic encounters? To what extent are such encounters a temporary source of respite from the pressures of day-to-day life or a deeper source of transformation? What are the implications of this for people living with life-long pressures or health conditions? Few studies have examined how the 'therapeutic' effect persists or wanes as people return to the more 'ordinary' spatio-temporal contexts of their day-to-day lives. Meanwhile, other researchers have problematized the visual hegemonies associated with notions of landscape (Macpherson, 2016), and a plethora of alternative terms have been employed in its stead. These include, for example, therapeutic 'networks' (Smyth, 2005), 'experiences' and 'environments' (Conradson, 2005), 'taskscapes' (Dunkley, 2009), 'mobilities' (Gatrell, 2013; Maddrell 2011), 'assemblage' (Foley, 2011) and 'enabling places' (Duff, 2012), with the latter gaining particular purchase amongst health and cultural geographers alike.

The interest in notions of assemblage and 'enabling' places stems in part from their relational and situated approaches to wellbeing, acknowledging the therapeutic nature of space as emergent in the context of dynamic sociocultural-material-affective-sensuous configurations involving both human and non-human actors (Gorman, 2016). This counters long-standing suggestions that places are somehow intrinsically therapeutic, arguing that positive place encounters 'derive from particular forms of socio-natural engagement' (Conradson, 2005: 338) which may change over time; for example with shifts in the materialities and meanings that constitute a setting (Kearns et al., 2014), the practices, mobilities and socialities unfolding in the setting (Gatrell, 2013; Doughty, 2013), and the needs, routines, priorities and embodied competences of those embroiled in the person-setting encounter (Bell et al., 2017). It has also been suggested that therapeutic effects can occur in the absence of physical encounter, through accessing therapeutic imaginaries (Gastaldo et al., 2004; Rose and Lonsdale, 2016). Central to many of these 
encounters are opportunities for positive experiences of relatedness, be it to non-judgemental others (human or non-human), to place assemblages perceived to mirror one's mood, to comforting memories of past places and people, or to the perceived presence of loved ones who have passed away and wider spiritual connections.

Despite increasing recognition of the multiplicity of ways of feeling well in place, studies have also highlighted the 'darker' side of such therapeutic assemblages, recognising their contested nature and the exclusionary geographies that can emerge through the often somewhat political nature of their discursive, social and material construction and reproduction. This was apparent within the care literature, for example, where the absence of certain bodies was noted in the context of informal care settings that are otherwise designed to promote feelings of inclusion and belonging (Glover et al., 2013). It has also been identified within the growing body of work advocating the therapeutic potential of 'green' and 'blue' space encounters; despite the rhetoric, certain bodies still feel 'out of place' in these settings, including those subjected to moral tropes around responsible lifestyles and obesity (Thomas, 2015).

Experiences of exclusion have led to concerns that the therapeutic needs and expectations of dominant groups can serve to marginalise those of others; an experience reflected in studies conducted with indigenous populations whose personal conceptions of wellbeing and mental health are undermined and supplanted by the imposition of traditional Western biomedical approaches (Gone, 2008; Goodkind et al., 2015), and in studies exploring the rise of medical tourism. For example, examining the therapeutic landscapes of medical tourism through a postcolonial lens, Buzinde and Yarnal (2012) explored how nations of the periphery are forced to negotiate the plentiful stereotypes held by the dominant core. Such destinations often use 'stereotypes that exoticize, sensualize and objectify' their lands in order to lure those in search of cheaper medical care (Buzinde and Yarnal, 2012: 786). Although these nations may use carnivalesque spaces and discourse to undermine hegemonic social ideologies, these attempts at subversion belie the reality that they remain an 'all-inclusive medical resort' servicing the dominant centre and conforming to 
their ideas and needs.

These exclusionary geographies have prompted concerns that access to so-called 'therapeutic landscapes' remains a 'privilege' of dominant groups within society (Conradson, 2014). This is apparent across multiple scales, from international flows of medical tourism (Buzinde and Yarnal, 2012), to national, regional and local inequalities in access to therapeutic resources (Glover et al., 2013; Giles-Vernick et al., 2016), to the micro-context of scientific research and 'experimental bodies'. With regards to the latter, for example, Greenhough (2012) expands routine conceptions of therapeutic space through an examination of the now defunct Common Cold Unit (CCU) in the UK, blurring the traditional boundary between experimental and therapeutic space. Greenhough highlights the risks of exclusion of certain bodies from clinical trials based on demographic factors, as well as global health inequities forcing populations in low-income countries to participate in clinical trials in order to access health care. This raises questions concerning the emergence of more 'radical' therapeutic landscapes; for example, studies have yet to understand how, when or why collective movements may arise to perhaps resist the therapeutic reputations of particular places at particular times.

The therapeutic landscapes concept has played a valuable role in sensitising and encouraging health geographers to critically engage with the myriad complexities and diverse embodied experiences underpinning the therapeutic/enabling qualities of person-place encounters e.g. by gender, ethnicity, physical mobility and social mobility. However, this complexity and depth may, to some extent, have limited the influence of this work outside of geography, for example within policy circles. Instead, terms such as 'healthy' and 'restorative' spaces have gained greater prominence through seemingly offering routes to health promotion that can be directly valued via economic means (UK National Ecosystem Assessment, 2014). Although laudable, this work could be improved through engaging with the broader dimensions advocated by the therapeutic landscapes concept, including the important cultural, historical and individual factors influencing the heterogeneity of people's place encounters over time, and the deep-seated material, social and 
discursive processes of exclusion that may be occurring for certain groups within these settings (Brown and Cummins, 2013; Carpenter, 2013). Engaging with this work could open up valuable opportunities to integrate a differently measured 'valuation' of more intangible aspects of therapeutic places and spaces.

\section{Conclusions: Healthy geographies}

Through this scoping review, we set out to explore how, where and to what benefit the 'therapeutic landscapes' concept has been applied to-date, and how such applications have contributed to its critical evolution as a relevant and useful concept in health geography. In the paper, we have framed recent work since 2007 as a 'third phase' (after two earlier editions by Williams in 1999, 2007), and charted key applications of the concept across its core material, social, spiritual and symbolic dimensions. In linking a third phase to 'third spaces', there is also an echo that links the present(s) of therapeutic landscapes to their past(s). Gesler's foundational work drew heavily from 1970s humanist geographies and especially the phenomenological turn pursued by Tuan, Relph, Buttimer and others (Gesler, 1992). From that same period, Seamon's work on lifeworlds and his explorations of the affective power of 'third space' has been rediscovered and resonates strongly with recent work noted in the care and spirituality sections above (Seamon, 1979). There is something about the ongoing power of particular 'third' places to act as nodes of wellness, precisely because of their open, mobile and connective value for multiple uses and users; a positive affective capacity uncovered in practice and immersion, in memory and identity formation.

The review has highlighted how the strengths of the concept (its ability to engage with complexity and flux, and its multi-dimensional and multi-scalar focus) have also limited its uptake and application across disciplines and within policy circles; although a recent special issue of 'Medicine Anthropology Theory' shows it still has purchase and potential (Winchester and McGrath, 2017). If the large and growing body of work on therapeutic landscapes (and more recent 
developments of the term) is to be effectively mobilised within relevant public health discourses and strategies, there is a need for robust and innovative empiricism that is legible both to other geographers and across relevant disciplines within and beyond academia. A fruitful way forward may require a looser attachment to the term itself, while recognising the pluralist nature of the other part of our title, healthy spaces, places and practices. This identifies the highly nuanced and emplaced nature of the work that differentiates so-called 'Therapeutic Landscapes and Environments' research from other subjects. A key challenge is to apply the concept to those marginalised on the global stage and within specific societies; likewise to be attentive to diversity and difference when considering who has access to and who benefits from settings that have developed socio-cultural reputations for health and/or healing, and how this changes over time. A further challenge is to echo the pluralism encompassed by current understandings of therapeutic landscapes, assemblages and practices in a range of methodologies that combine evocative experiential narratives with more tangible physiological and psychological measures that will resonate with public health audiences and further enrich the life of a rare example of a concept that has moved beyond the bounds of its origins in medical/health geography. 


\section{References}

Agyekum, B., Newbold, B.K. 2016. Religion/spirituality, therapeutic landscape and immigrant mental well-being amongst African immigrants to Canada. Mental Health, Religion and Culture, doi: http://dx.doi.org/10.1080/13674676.2016.1225292

Andrews, G.J. 2004. (Re)thinking the dynamics between healthcare and place: therapeutic geographies in treatment and care practices. Area, 36(3): 307-318

Andrews, G.J., Kearns, R.A., Kingsbury, P., Carr, E.R. 2011. Cool aid? Health, wellbeing and place in the work of Bono and U2. Health \& Place, 17(1): 185-194.

Arksey, H., O'Malley, L. 2005. Scoping studies: towards a methodological framework. International Journal of Social Research Methodology, 8(1): 19-32.

Bagelman, J. 2013. Sanctuary: A Politics of Ease? Alternatives: Global, Local, Political, 38(1): 49-62.

Bell, S.L., Phoenix, C., Lovell, R., Wheeler, B.W. 2014. Green space, health and wellbeing: making space for individual agency. Health \& Place, 30: 287-292.

Bell, S.L., Phoenix, C., Lovell, R., Wheeler, B.W. 2015. Seeking everyday wellbeing: The coast as a therapeutic landscape. Social Science and Medicine, 142: 56-67.

Bell, S.L., Wheeler, B.W., Phoenix, C. 2017. Using geo-narratives to explore the diverse temporalities of therapeutic landscapes: perspectives from 'green' and 'blue' settings. Annals of the Association of American Geographers, 107(1): 93-108.

Bigante, E. 2015. Therapeutic landscapes of traditional healing: building spaces of well-being with the traditional healer in St. Louis, Senegal. Social \& Cultural Geography, 16(6), 698-713.

Bourdieu, P., Wacquant, L.J.D. 1992. Symbolic Violence. In: Bourdieu, P., Wacquant, L.J.D (Eds) An Invitation to Reflexive Sociology. Chicago: University of Chicago Press, Chapter 32.

Brewster, L. 2014. The public library as therapeutic landscape: A qualitative case study. Health \& Place, 26: 94-99. 
Brown, K.M. 2016. The haptic pleasures of ground-feel: The role of textured terrain in motivating regular exercise. Health and Place, doi: http://dx.doi.org/10.1016/i.healthplace.2016.08.012.

Brown, T., Cummins, S. 2013. Intervening in health: The place of urban green space. Landscape and Urban Planning, 118: 59-61.

Burns, N., Paterson, K. and Watson, N. 2009. An inclusive outdoors? Disabled people's experiences of countryside leisure services. Leisure Studies, 28(4): 403-419.

Burns, N., Watson, N. and Paterson, K. 2013 Risky bodies in risky spaces: disabled people's pursuit of outdoor leisure. Disability and Society, 28(8): 1059-1073.

Butterfield, A., Martin, D. 2016. Affective sanctuaries: understanding Maggie's as therapeutic landscapes. Landscape Research, 41(6): 695-70.

Buzinde, C.N., Yarnal, C. 2012. Therapeutic landscapes and postcolonial history: A theoretical approach to medical tourism. Social Science and Medicine, 74(5): 783-787.

Carpenter, M. 2013. From 'healthful exercise' to 'nature on prescription': The politics of urban green spaces and walking for health. Landscape and Urban Planning, 118: 120-127.

Carter, A., Greene, S., Nicholson, V., O’Brien, N., Dahlby., de Pokomandy, A., Loutfy, M.R., Kaida, A., and on behalf of the CHIWOS Research Team. 2016. 'It's a very isolating world': the journey to HIV care for women living with HIV in British Columbia, Canada. Gender, Place \& Culture, 23(7): 941-954.

Cattell, V., Dines, N., Gesler, W., Curtis, S. 2008. Mingling, observing, and lingering: everyday public spaces and their implications for wellbeing and social relations. Health \& Place, 14: 544-561.

Chakrabarti, R. 2010. Therapeutic networks of pregnancy care: Bengali immigrant women in New York City. Social Science \& Medicine, 71: 362-369.

Coleman, T., Kearns, R., 2015. The role of blue spaces in experiencing place, aging and wellbeing: Insights from Waiheke Island, New Zealand. Health \& Place, 35: 206-217. 
Collins, J., Avey, S., Lekkas, P. 2016. Lost landscapes of healing: the decline of therapeutic mental health landscapes. Landscape Research, 41(6): 664-677.

Conradson, D. 2003. Spaces of care in the city: the place of a community drop-in centre. Social \& Cultural Geography, 4(4): 507-525.

Conradson, D. 2005. Landscape, care and the relational self: Therapeutic encounters in rural England. Health \& Place, 11: 337-348.

Conradson, D. 2007. The Experiential Economy of Stillness: Places of Retreat in Contemporary Britain. In A. Williams (Ed.), Therapeutic Landscapes (33-48). Hampshire, UK: Ashgate Publishing Limited.

Conradson, D. 2014. Health and well-being. In: Cloke, P., Crang, P., Goodwin, M. (Eds) Introducing Human Geographies, Third Edition. Abingdon: Routledge, 599-612.

Cooper Marcus, C., Sachs, N., 2013. Therapeutic Landscapes: An Evidence-Based Approach to Designing Healing Gardens and Restorative Outdoor Spaces. Wiley: NY.

Curtis, S., Gesler, W., Fabian, K., Francis, S., Priebe, S. 2007. Therapeutic landscapes in hospital design: a qualitative assessment by staff and service users of the design of a new mental health inpatient unit. Environment and Planning C: Government and Policy, 25: 591-610.

Curtis, S., Gesler, W., Priebe, S., Francis, S. 2009. New spaces of inpatient care for people with mental illness: A complex 'rebirth' of the clinic? Health \& Place, 15: 340-348.

Darling, J. 2017. Forced migration and the city: Irregularity, informality, and the politics of presence. Progress in Human Geography, 41(2): 178-198.

Doughty, K. 2013. Walking together: The embodied and mobile production of a therapeutic landscape. Health \& Place, 24: 140-146.

Duff, C. 2012. Exploring the role of 'enabling places' in promoting recovery from mental illness. A qualitative test of a relational model. Health \& Place, 18: 1388-1395. 
Dunkley, C.M. 2009. A therapeutic taskscape: Theorizing place-making, discipline and care at a camp for troubled youth. Health \& Place, 15: 88-96.

Dyck, I., Dossa, P. 2007. Place, health and home: Gender and migration in the constitution of healthy space. Health \& Place, 13(3): 691-701.

Eastoe, S. 2016. 'Relieving gloomy and objectless lives'. The landscape of Caterham Imbecile Asylum. Landscape Research, 41(6): 652-663.

Edensor, T. 2012. Illuminated atmospheres: anticipating and reproducing the flow of affective experience in Blackpool. Environment and Planning D: Society and Space, 30: 1103-1122.

Edgley, A., Pilnick, A., Clarke, M. 2011. 'The air still wasn't good ... everywhere I went I was surrounded': Lay perceptions of air quality and health'. Health Sociology Review, 20(1): 97-108.

El-Bialy, R., Mulay, S. 2015. Two Sides of the Same Coin: Factors that Support and Challenge the Wellbeing of Refugees in a Small Urban Centre. Health \& Place, 35: 52-59.

English, J., Wilson, K., Keller-Olaman, S. 2008. Health, healing and recovery: Therapeutic landscapes and the everyday lives of breast cancer survivors. Social Science \& Medicine, 67: 68-78.

Evans, J.D., Crooks, V.A., Kingsbury, P.T. 2009. Theoretical injections: On the therapeutic aesthetics of medical spaces. Social Science \& Medicine, 69: 716-721.

Evans, J. 2014. Painting therapeutic landscapes with sound: On Land by Brian Eno. In: Andrews, G.J., Kingsbury, P., Kearns, R.A. (Eds) Soundscapes of Wellbeing in Popular Music. London: Ashgate. Chapter 12: 173-187.

Findlay, J., Franke, T., McKay. H., Sims-Gould, J. 2015. Therapeutic landscapes and wellbeing in later life: Impacts of blue and green spaces for older adults. Health \& Place, 34: 97-106.

Foley, R. 2011. Performing health in place: the holy well as a therapeutic assemblage. Health \& Place, 17: 470-479. 
Foley, R. 2013. Small health pilgrimages: Place and practice at the holy well. Culture and Religion, 14(1): 44-62.

Foley, R. 2015. Swimming in Ireland: Immersions in therapeutic blue space. Health \& Place, 35: 218225.

Foley, R., Kistemann, T. 2015. Blue Space Geographies: Enabling Health in Place. Introduction to Special Issue on Healthy Blue Space. Health \& Place, 35: 157-165.

Gastaldo, D., Andrews, G.J., Khanlou, N. 2004. Therapeutic landscapes of the mind: theorizing some intersections between health geography, health promotion and immigration studies. Critical Public Health, 14(2): 157-176.

Gatrell, A.C. 2013. Therapeutic mobilities: walking and 'steps' to wellbeing and health. Health \& Place, 22: 98-106.

Gesler, W. 1992. Therapeutic landscapes: Medical issues in the light of the new cultural geography. Social Science \& Medicine, 34: 735-746.

Gesler, W. 1993. Therapeutic landscapes: theory and a case study of Epidauros, Greece. Environment and Planning $D, 11:$ 171-189.

Gesler, W. 1996. Lourdes: healing in a place of pilgrimage. Health \& Place, 2: 95-105.

Gesler, W. 1998. Bath's reputation as a healing place. In: Kearns, R., Gesler, W. (Eds) Putting Health into Place. Syracuse, NY: Syracuse University Press.

Gesler, W. 2003. Healing Places. Maryland, US: Rowman \& Littlefield.

Giles-Vernick, T., Bainilago, L., Fofana, M., Bata, P., Vray, M. 2016. Home care of children with diarrhoea in Bangui's Therapeutic Landscape (Central African Republic). Qualitative Health Research, 26(2): 164-175.

Glover, T.D., Parry, D.C. 2009. A third place in the everyday lives of people living with cancer: Functions of Gilda's Club of Greater Toronto. Health \& Place, 15: 97-106. 
Glover, T.D., Parry, D.C., Mulcahy, C.M. 2013. At once liberating and exclusionary? A Lefebvrean analysis of Gilda's Club of Toronto. Leisure Studies, 32(5): 467-486.

Gone, J. 2008. "So I can be like a Whiteman": The Cultural Psychology of Space and Place in American Indian Mental Health. Culture and Psychology, 14(3): 369-399.

Goodkind, J.R., Gorman, B., Hess, J.M., Parker, D.P., Hough, R.L. 2015. Reconsidering culturally competent approaches to American Indian Healing and Well-being. Qualitative Health Research, 25(4): 486-499.

Gorman, R. 2016. Therapeutic landscapes and non-human animals: the roles and contested positions of animals within care farming assemblages. Social and Cultural Geography, 18:3, 315-335.

Grant, M.J., Booth, A. 2009. A typology of reviews: an analysis of 14 review types and associated methodologies. Health Information and Libraries Journal, 26: 91-108.

Greenhough, B. 2012. Room with a rhinovirus? Blurring the boundaries between research and therapeutic space. Transactions of the Institute of British Geographers, 37(3): 402-417.

Harris, A. 2013. Lourdes and holistic spirituality: Contemporary Catholicism, the therapeutic and religious thermalism. Culture and Religion, 14(1), 23-43.

Houghton, F., Houghton, S. 2015. Therapeutic micro-environments in the Edgelands: A thematic analysis of Richard Mabey's The Unofficial Countryside. Social Science \& Medicine, 133: 280-286.

Kearns, R., Collins, D., Conradson, D. 2014. A healthy island blue space: From space of detention to site of sanctuary. Health \& Place, 30: 107-115.

Kestens, J., Thierry, B., Chaix, B. 2016. Re-creating daily mobility histories for health research from raw GPS tracks: Validation of a kernel-based algorithm using real-life data. Health \& Place, 40: 29-33. Laws, J. 2009. Reworking therapeutic landscapes: The spatiality of an 'alternative' self-help group. Social Science \& Medicine, 69: 1827-1833.

Lea, J. 2008 Retreating to Nature: Rethinking 'Therapeutic Landscapes'. Area, 40(1): 90-98. 
Lengen, C. 2015. The effects of colours, shapes and boundaries of landscapes on perception, emotion and mentalising processes promoting health and well-being. Health \& Place, 35: 166-177.

Liamputtong, P., Suwankhong, D. 2015. Therapeutic landscapes and living with breast cancer: The lived experiences of Thai women. Social Science \& Medicine, 128: 263-271.

Love, M., Wilton, R., DeVerteuil, G. 2012. 'You have to make a new way of life': women's drug treatment programmes as therapeutic landscapes in Canada. Gender, Place \& Culture, 19(3): 382396.

MacKian, S.C. 2008. What the papers say: Reading therapeutic landscapes of women's health and empowerment in Uganda. Health \& Place, 14: 106-115.

Macpherson, H. 2016. Walking with visual impairments in the British countryside: Picturesque legacies, collective enjoyments and well-being benefits. Journal of Rural Studies, doi: http://dx.doi.org/10.1016/j.jrurstud.2016.10.001.

Maddrell A. 2011. 'Praying the Keeills'. Rhythm, meaning and experience on pilgrimage journeys in the Isle of Man. Landabrefid, 25: 15-29

Maddrell, A. 2013. Moving and being moved: More-than-walking and talking on pilgrimage walks in the Manx landscape. Culture and Religion, 14(1), 63-77.

Maddrell, A., della Dora, V., Scafi A., Walton, H. 2015. Christian pilgrimage, landscape and heritage. Journeying to the sacred. Routledge: London

Maddrell, A., della Dora, V. 2013a. Editorial, Spaces of Renewal. Journal of Culture and Religion, 14 (1): $1-7$

Maddrell, A., della Dora, V. 2013b. Crossing Surfaces in search of the Holy: Landscape and Liminality in Contemporary Christian Pilgrimage. Environment and Planning A, 45: 1104-1126

Maddrell, A., Scriven, R. 2016. Celtic pilgrimage, past and present: from historical geographies to contemporary embodied practices, Social and Cultural Geography 17 (2) 300-321. 
Meijering, L., Lettinga, A.T., Nanninga, C.S. and Milligan, C. 2016 Interpreting therapeutic landscape experiences through rural stroke survivors' biographies of disruption and flow. Journal of Rural Studies, doi: http://dx.doi.org/10.1016/j.jrurstud.2016.06.004.

Milligan, C., Bingley, A. 2007. Restorative places or scary spaces? The impact of woodland on the mental well-being of young adults. Health \& Place, 13: 799-811.

Milligan, C., Payne, S., Bingley, A., Cockshott, Z. 2015. Place and wellbeing: shedding light on activity interventions for older men. Ageing and Society, 35(1): 124-149.

Moore, A., Carter, B., Hunt, A., Sheikh, K. 2013. 'I am closer to this place' - Space, place and notions of home in lived experiences of day care. Health \& Place, 19: 151-158.

Muir-Cochrane, E., Oster, C., Grotto, J., Gerace, A., Jones, J. 2013. The inpatient psychiatric unit as both a safe and unsafe place: Implications for absconding. International Journal of Mental Health Nursing, 22: 304-312.

Nettleton, S. 2015. Fell runners and walking walls: towards a sociology of living landscapes and aesthetic atmospheres as an alternative to a Lakeland picturesque. The British Journal of Sociology, 66(4): 759-778.

Notermans, C., Turolla, M. and Jansen, W. 2016. Caring and connecting: reworking religion, gender and families in post-migration life. In Gemzöe, L., Keinänen, M. and Maddrell A. (Eds.) Contemporary Encounters in Gender and Religion. European perspectives. Palgrave Macmillan: London. 241-258 Panelli, R., Tipa, G. 2007. Placing Well-Being: A Maori Case Study of Cultural and Environmental Specificity. Ecohealth, 4(4): 445-460.

Panelli, R. 2008. Social geographies: encounters with Indigenous and more-then-White/Anglo geographies. Progress in Human Geography, 32(6): 801-811.

Parent, L. 2016. The wheeling interview: mobile methods and disability. Mobilities, 11: 521-532. 
Parr, H. 1997. Mental health, public space, and the city: Questions of individual and collective access. Environment and Planning D: Society and Space, 15: 434-454.

Parry, D.C., Glover, T.D. 2010. Dignity, Hope and Transcendence: Gilda's Club as Complementary Care for Cancer Survivors. Journal of Leisure Research, 42(3): 347-364.

Pearce, J., Shortt, N., Rind, E., Mitchell, R. 2016. Life Course, Green Space and Health: Incorporating Place into Life Course Epidemiology. International Journal of Environmental Research and Public Health, 13(3): 331-342.

Phillips, R., Evans, B., Muirhead, S. 2015. Curiosity, place and wellbeing: encouraging place-specific curiosity as a 'way to wellbeing'. Environment and Planning A, 47: 2339-2354.

Pitt, H. 2014. Therapeutic experiences of community gardens: putting flow in its place. Health \& Place, 27: 84-91.

Plane, J., Klodawsky, F. 2013. Neighbourhood amenities and health: Examining the significance of a local park. Social Science \& Medicine, 99: 1-8.

Rodaway, P. 1994. Sensuous Geographies: Body, sense and place. Routledge: Abingdon.

Rose, E., Lonsdale, S. 2016. Painting place: Re-imagining landscapes for older people's subjective wellbeing. Health \& Place, 40: 58-65.

Sampson, R., Gifford, S.M. 2010. Place-making, settlement and wellbeing: The therapeutic landscapes of recently arrived youth with refugee backgrounds. Health \& Place, 16(1): 116-131.

Seamon, David, 1979. A Geography of the Lifeworld. Croom Helm: London.

Smith, K., Luginaah, I., Lockridge, A. 2010. "Contaminated" Therapeutic Landscape: The Case of the Aamjiwnaang First Nation in Ontario, Canada. Geography Research Forum, 30: 66-87.

Smith, T.S.J., Reid, L. 2017. Which 'being' in wellbeing? Ontology, wellness and the geographies of happiness? Progress in Human Geography, doi: 10.1177/0309132517717100. 
Smyth, F. 2005. Medical geography: therapeutic places, spaces and networks. Progress in Human Geography, 29: 488-495.

Spinney, J. 2006. A place of sense: a kinaesthetic ethnography of cyclists on Mont Ventoux. Environment and Planning D: Society and Space, 24: 709-732.

Straughan, E. 2012. Touched by water: The body in scuba diving. Emotion, Space \& Society, 5: 19-26.

Thomas, F. 2015. The role of natural environments within women's everyday health and wellbeing in Copenhagen, Denmark. Health \& Place, 35: 187-195.

UK National Ecosystem Assessment. 2014. The UK National Ecosystem Assessment: Synthesis of Key Findings. UNEP-WCMC, LWEC, UK.

Völker, S., Kistemann, T., 2013. I'm always entirely happy when I'm here! urban blue enhancing human health and well-being in Cologne and Düsseldorf, Germany. Social Science \& Medicine, 78 : $113-124$.

Völker, S., Kistemann, T. 2015. Developing the urban blue: Comparative health responses to blue and green urban open spaces in Germany. Health \& Place, 35: 196-205.

Wakefield, S., McMullan, C. 2005. Healing in places of decline: (re)imagining everyday landscapes in Hamilton, Ontario. Health \& Place, 11: 299-312.

Warner, J., Talbot, D., Bennison, G. 2013. The café as affective community space: Reconceptualising care and emotional labour in everyday life. Critical Social Policy, 33(2): 305-324.

Wendt, D.C., Gone, JP. 2012. Urban indigenous therapeutic landscapes: A case study of an urban American Indian health organisation. Health \& Place, 18(5): 1025-1033.

Williams, A (Ed). 1999. Therapeutic Landscapes: The dynamic between place and wellness. Maryland: University Press of America.

Williams, A (Ed). 2007. Therapeutic Landscapes. Surrey: Ashgate Publishing Ltd. 
Williams, A. 2010. Therapeutic Landscapes as Health-promoting Places. In, Brown, T., McLafferty, S. and Moon, G. (Eds) A Companion to Health and Medical Geography. Chichester, Wiley-Blackwell, 207-233.

Williams, A. 2013. Surfing therapeutic landscapes: Exploring cyberpilgrimage. Culture and Religion, 14(1): 78-93.

Williams, A. 2016. Spiritual landscapes of Pentecostal worship, belief, and embodiment in a therapeutic community: New critical perspectives. Emotion, Space \& Society, 19: 45-55.

Willis, A. 2009. Restorying the self, restorying place: Healing through grief in everyday places. Emotion, Space \& Society, 2: 86-91.

Winchester, M., McGrath, J. 2017. Therapeutic landscapes: Anthropological perspectives on health and place. Medicine Anthropology Theory, 4(1): i-x.Wood, V.J., Curtis, S.E., Gesler, W., Spencer, I.H., Close, H.J., Mason, J., Reilly, J.G. 2013a. Spaces for smoking in a psychiatric hospital: Social capital, resistance to control, and significance for 'therapeutic landscapes'. Social Science \& Medicine, 97: $104-111$.

Wood, V.J., Curtis, S.E., Gesler, W., Spencer, I.H., Close, H.J., Mason, J., Reilly, J.G. 2013b. Creating 'therapeutic landscapes' for mental health carers in inpatient settings: A dynamic perspective on permeability and inclusivity. Social Science \& Medicine, 91: 122-129.

Wood, V.J., Gesler, W., Curtis, S.E., Spencer, I.H., Close, H.J., Mason, J., Reilly, J.G. 2015. 'Therapeutic landscapes' and the importance of nostalgia, solastalgia, salvage and abandonment for psychiatric hospital design. Health \& Place, 33: 83-89. 